\title{
Short-term outcomes of the surgical management of acquired rectourethral fistulas: does technique matter?
}

\author{
Valentine N Nfonsam' \\ James JL Mateka ${ }^{2}$ \\ Andrew D Prather ${ }^{2}$ \\ Jorge E Marcet ${ }^{2}$ \\ 'Department of Surgery, College \\ of Medicine, University of Arizona, \\ Tucson, AZ, USA; ${ }^{2}$ Department \\ of Surgery, College of Medicine, \\ University of South Florida, Tampa, \\ FL, USA
}

Correspondence: Valentine N Nfonsam Department of Surgery, University of Arizona, I50I North Campbell Avenue, Tucson, AZ 85724, USA Email vnfonsam@surgery.arizona.edu
This article was published in the following Dove Press journal:

Research and Reports in Urology

29 January 2013

Number of times this article has been viewed

Background: Acquired rectourethral fistulas are uncommon and challenging to repair. Most arise as a complication of prostate cancer treatment. Several procedures have been described to repair rectourethral fistulas with varying outcomes. We review the etiology, management, and outcomes of patients with rectourethral fistulas at our institution.

Materials and methods: A retrospective review of patients undergoing repair of rectourethral fistulas was undertaken. Data were collected on patient demographics, fistula etiology, operative procedure, fecal and urinary diversion, and clinical outcome. Patients with urinary and/or fecal diversion underwent radiographic evaluation to confirm closure of the fistula prior to reversal of the diversion.

Results: Fistula repair was performed on 22 patients from 1999 to 2009 . All the patients were male of an average age of 69 years (range: $39-82$ years). All patients, except one, had prostate cancer. Fistula formation was associated with radiotherapy in $54.4 \%$ of patients, brachytherapy in $36.4 \%$ of patients, and with external beam radiation therapy in $18.2 \%$ of patients. Other causes included prostatectomy (seven patients, 31.8\%), cryotherapy (two patients, 9.1\%), and perianal abscess (one patient, 4.5\%). Procedures performed for fistula repair included transanal repair (eleven patients, 50\%), transperineal repair (five patients, $22.7 \%$ ), transabdominal repair (three patients, 13.6\%), and York-Mason repair (three patients, 13.6\%). Fourteen patients $(63.6 \%)$ had urinary diversion. Fecal diversion was performed in 16 (72.7\%) patients. Five (22.7\%) patients had had previous attempts at fistula repair. Of the 22 patients treated, repair was successful in 20 patients (91\%). The average follow-up time was 6 months (range: 3-13 months).

Conclusion: The success rate of treatment of rectourethral fistulas is high, regardless of the procedure type. Patients with previous repair attempts tend to have less favorable outcomes. With high success rates, less invasive procedures should be attempted first.

Keywords: rectourethral, fistula, management, York-Mason, colostomy, cancer, transanal, transperineal, radiation, prostate

\section{Introduction}

Rectourethral fistulas (RUF), either congenital or acquired, pose a significant treatment challenge. The etiologies of acquired RUF are mostly iatrogenic in nature, and RUF may occur secondarily to treatment for prostate cancer. These treatments include radical prostatectomy, radiotherapy, cryotherapy, and brachytherapy of the prostate. ${ }^{1}$ Less common causes include infectious and inflammatory diseases as well as genitourinary trauma. ${ }^{2,3}$ Acquired RUF caused by radiation to the prostate rarely close spontaneously; ${ }^{1-4}$ however, very small fistulas not caused by radiation therapy have been shown to close spontaneously after fecal and urinary diversion. ${ }^{5}$ 
Typical symptoms of RUF include pneumaturia, fecaluria, dysuria, and discharge of urine per rectum during micturation. ${ }^{6,7}$ Patients also complain of dysuria and are found to have recurrent cystitis. ${ }^{6}$ These symptoms are alleviated by treatment with antibiotics, as well as urinary and fecal diversion. However, definitive surgical management of the fistula is still required even after diversion for the fistula to ultimately close. Diagnosis of RUF is made mostly from the patient's history and presenting symptoms. Rectal examination under anesthesia, proctoscopy, contrast enema study, and cystourethroscopy also aid significantly in diagnosis. ${ }^{7}$

Several surgical techniques have been employed over the years to manage RUF. Transanal repair of RUF has been described by Hata et $\mathrm{al}^{8}$ in 2002 and Razi et $\mathrm{al}^{9}$ in 2008. Options for this approach include an endoanal advancement flap or layered closure. Other described surgical management options for RUF include graciloplasty, ${ }^{10-12}$ York-Mason technique, ${ }^{6,13-15}$ and transperineal repair. Treatment of fistulas with fibrin glue as well as with dartos flap interposition has also been described. ${ }^{16,17}$ Despite the various techniques described to repair RUF, there is still not a single most effective procedure or a clear optimal approach to their management.

The aim of this study is to review our experience in the surgical treatment of RUF using various techniques and to evaluate whether treatment outcomes are affected by the technique used.

\section{Materials and methods}

After receiving institutional review board approval, we performed a retrospective chart review of patients who had undergone repair of RUF. Data were collected on patient demographics, etiology of fistula, operative procedure, number of previous repair attempts, length of follow-up, fecal and urinary diversion, and clinical outcome.

Most of the patients had urinary and/or fecal diversion prior to fistula repair, but this was not an absolute requirement. Urinary diversion procedures, which were performed by a urologist, included the placement of a suprapubic catheter, creation of the continent urinary (Florida) pouch, or the placement of an indwelling Foley catheter. Fecal diversion was achieved with colostomy or ileostomy. Patients not already diverted were considered for diversions when there was clinical or radiographic evidence of pelvic sepsis. Some patients presented to our institution with urinary and/or fecal diversion.

Success was defined as no fistula identified on physical exam, as well as on Gastrografin enema studies and cystoscopy, which were performed on patients with fecal and urinary diversion, respectively. Only after fistula closure had been ascertained was the reestablishment of fecal continuity performed. Thereafter, patients were seen only when they were symptomatic.

The transanal repair of the fistula is performed as described by Vidal et al, ${ }^{2}$ with the patient placed in the prone jackknife position. A retractor is placed into the rectum and the fistula is identified. The fistula is then debrided of nonviable tissue. A transverse incision is made through the fistula, and lateral flaps are raised. The fistula is then closed in multiple layers using 3-O absorbable monofilament sutures.

Transabdominal fistula repairs were done for patients with very large fistulas who ultimately had a cystectomy and a prostatectomy. These included low anterior resections with coloanal anastomosis, and at times included abdominoperineal resections.

Three modified York-Mason procedures were done with the gracilis muscle flap used to reinforce the repair. The patient is placed in a prone jackknife position and an incision is made from the anal margin to the coccyx. ${ }^{6}$ The anal sphincters and the puborectalis are then incised, exposing the anterior wall of the rectum and the fistula. The fistula tract is excised and closed using absorbable sutures. A gracilis muscle flap is harvested, inserted, and secured in the perineum space over the repaired fistula. The posterior anal sphincters and the puborectalis muscle are then sutured closed in layers.

For the transperineal repair procedure, the patient is placed in a modified lithotomy position, while the rectum is separated from the prostate and the fistula is repaired. Three of the patients had gracilis muscle flap reinforcement as described by Wexner et al. ${ }^{12}$ One patient had a tunica vaginalis interposition flap, and one had a layered primary suture repair.

The decision surrounding the type of operation that was needed to be done was based on the size of the fistula, the amount of radiation damage to surrounding tissue, the distance from the anal verge, and also on the surgeon; the York-Mason procedure was preferred by the urologists. A flap repair was performed if there was concern about the viability of the tissue surrounding the fistula.

The patients were seen in clinic 2 weeks after their operation and every 2 months subsequently as a routine postoperative visit and also as a follow-up visit. The patients that had any concerns about their operation were brought back to clinic earlier than their routinely scheduled clinic appointment. The patients who had urinary or fecal diversion were also seen in clinic before and after reversal. 


\section{Results}

From 1999 to 2009, 22 patients underwent repair of RUF. All the patients were male and they had an average age of 69 years (range: $39-82$ years). All patients had a diagnosis of and had been treated for prostate cancer, except one patient who had a perianal abscess and fistula from Crohn's disease. In the majority of the patients (12 patients, 54.4\%), fistula formation was associated with some form of radiotherapy, brachytherapy (eight patients, 36.4\%), and external beam radiation therapy (four patients, 18.2\%). Fistula formation was also seen in seven patients $(31.8 \%)$ who had undergone a prostatectomy, which was complicated with injury to the rectum. Despite primary repair of the rectal injury, the patients later developed a fistula. Cryotherapy (two patients, 9.1\%) and perianal abscess (one patient, 4.5\%) were also causes of fistula formation (Table 1).

Transanal repair of the fistula was performed in eleven patients $(50 \%)$. This was done as a layered closure using absorbable sutures after the fistula had been debrided. Transperineal repair was performed in five patients $(22.7 \%)$, transabdominal repair in three patients $(13.6 \%)$, and York-Mason repair in three patients (13.6\%). Fourteen patients $(63.6 \%)$ had some form of urinary diversion; 12 patients had a suprapubic catheter, one had a chronic indwelling catheter, and one had a Florida pouch. Fecal diversion was performed in 16 patients $(72.7 \%)$; 15 patients $(68.2 \%)$ underwent a colostomy, and one patient $(4.5 \%)$ had an ileostomy (Table 2). In all, five patients (22.7\%) had undergone previous attempts at fistula repair. Four of the patients had just one previous attempt, and one patient had four previous attempts. The gracilis muscle flap was used in six patients - three in the York-Mason procedure and three in the transperineal repair.

Of the 22 patients treated, repair was successful in 20 patients $(91 \%)$. The average follow-up time was 6 months (range: 3-13 months). The two patients who had a failed repair had one previous attempted repair.

Table I Patient characteristics

Total number of patients: 22

Average age: 69 years

Prostate cancer: 2 I patients (95.5\%)

Etiology of fistulas:

Radiation

Brachytherapy

External beam radiation

Prostatectomy

Cryotherapy

Perianal abscess

Eight patients (36\%)

Four patients (18.2\%)

Seven patients (31.8\%)

Two patients (9.1\%)

One patient (4.5\%)
One of the patients had a transanal repair and the other had a transperineal repair of their fistula. The failed transperineal repair was done without a gracilis muscle buttress. One of the failed repairs had no urinary diversion, and the other had no fecal diversion. Repair was successful in all of the patients that had gracilis muscle transposition grafts.

\section{Discussion}

Acquired RUF are uncommon, but management of them poses a major challenge. They are also very distressing to the patient, affecting quality of life, while also causing not only persistent urinary tract infections and pyelonephritis, but also perineal sepsis.

These fistulas are mostly seen in patients with prostate cancer who have undergone radiation therapy and/or prostatectomy. Our study demonstrated that $54.4 \%$ of patients with RUF had had some form of radiation therapy. This is in concert with recent studies that have been conducted since 1998 that have shown that $49.6 \%$ of patients with RUF had exposure to pelvic radiation. ${ }^{18}$ RUF have also been seen in patients with Crohn's disease, but this is very rare; this was shown in our previous study, in which only one patient's fistula was caused by Crohn's disease. ${ }^{17-19}$

In our study, $91 \%$ of the patients were successfully treated with the use of various techniques. We defined success as the complete closure of the fistula as demonstrated by physical exam, gastrograffin enema studies, and cystoscopy. This high rate of success in treating RUF has been demonstrated by various investigators also using different surgical techniques. Zmora et $\mathrm{al}^{11}$ showed that ten $(83 \%)$ out of 12 patients who underwent a gracilis muscle transposition for iatrogenic RUF healed, with the remaining two patients healing after further surgical procedures. ${ }^{11}$ In our study, repair was also successful in all six patients that had gracilis muscle transposition either in combination with the York-Mason procedure or with transperineal repair. Razi et $\mathrm{al}^{9}$ also demonstrated a $100 \%$ fistula closure in five patients who were treated with transanal repair. The York-Mason repair was performed on eight patients by Crippa et al, ${ }^{6}$ and there was $100 \%$ fistula closure with no recurrence. This therefore demonstrates that there is not one individual technique that is the best in the management of RUF.

This phenomenon is also seen in our study where there were no significant differences in fistula healing between the different procedures, though the number is too small to statistically assess this. More importantly, to achieve this maximum healing, the fistula tract has to be debrided to 
Table 2 Numeric result presentation

\begin{tabular}{|c|c|c|c|c|c|}
\hline & Total & Success (n) & $\begin{array}{l}\text { Percent } \\
\text { of patients }\end{array}$ & $\begin{array}{l}\text { Failure } \\
\text { (n) }\end{array}$ & $\begin{array}{l}\text { Percent } \\
\text { of patients }\end{array}$ \\
\hline \multicolumn{6}{|l|}{ Diagnosis } \\
\hline Prostate cancer & 21 & 19 & $90.48 \%$ & 2 & $9.52 \%$ \\
\hline Abscess & 1 & 1 & $100.00 \%$ & 0 & $0.00 \%$ \\
\hline \multicolumn{6}{|l|}{ Etiology } \\
\hline Brachytherapy & 8 & 7 & $87.50 \%$ & 1 & $12.50 \%$ \\
\hline prostatectomy & 7 & 7 & $100.00 \%$ & 0 & $0.00 \%$ \\
\hline EBRT & 4 & 3 & $75.00 \%$ & 1 & $25.00 \%$ \\
\hline Cryotherapy & 2 & 2 & $100.00 \%$ & 0 & $0.00 \%$ \\
\hline Abscess & 1 & I & $100.00 \%$ & 0 & $0.00 \%$ \\
\hline \multicolumn{6}{|l|}{ Repair type } \\
\hline Transanal & 11 & 10 & $90.91 \%$ & 1 & $9.09 \%$ \\
\hline Transperineal & 5 & 4 & $80.00 \%$ & 1 & $20.00 \%$ \\
\hline Transabdominal & 3 & 3 & $100.00 \%$ & 0 & $0.00 \%$ \\
\hline York-Mason & 3 & 3 & $100.00 \%$ & 0 & $0.00 \%$ \\
\hline \multicolumn{6}{|c|}{ Urinary diversion } \\
\hline Suprapubic & 12 & 11 & $91.67 \%$ & 1 & $8.33 \%$ \\
\hline Catheter & 1 & 1 & $100.00 \%$ & 0 & $0.00 \%$ \\
\hline Florida pouch & 1 & 1 & $100.00 \%$ & 0 & $0.00 \%$ \\
\hline None & 8 & 7 & $87.50 \%$ & 1 & $12.50 \%$ \\
\hline \multicolumn{6}{|l|}{ Fecal diversion } \\
\hline Colostomy & 15 & 15 & $100.00 \%$ & 0 & $0.00 \%$ \\
\hline Ileostomy & 1 & 0 & $0.00 \%$ & 1 & $100.00 \%$ \\
\hline None & 6 & 5 & $83.33 \%$ & 1 & $16.67 \%$ \\
\hline \multicolumn{6}{|c|}{ Previous attempts } \\
\hline Yes & 5 & 3 & $60.00 \%$ & 2 & $40.00 \%$ \\
\hline No & 17 & 17 & $100.00 \%$ & 0 & $0.00 \%$ \\
\hline
\end{tabular}

Abbreviation: EBRT, external beam radiation therapy.

healthy tissue, especially in patients with a history of pelvic radiation. Hyperbaric oxygen has been used after radiation to improve healing.

We also did not observe any difference in fistula closure between patients who did and those who did not have a urinary and/or fecal diversion. For this reason, fecal diversion was not routinely done. This is in accordance with previous studies that have been done to address this issue. In a previous study that involved 13 repairs, Stephenson and Middleton ${ }^{20}$ demonstrated that having a colostomy was unnecessary, and that it in fact has a negative impact on patient quality of life. Sonoda et $\mathrm{al}^{21}$ also showed that a diverting colostomy prior to repair of the fistula was of no added value. However, we do agree that fecal diversion is clearly of value in patients with systemic and perineal sepsis. ${ }^{22}$

The two patients who failed fistula repair in our study both had previous repairs. The number of patients in our study is too small to suggest a definitive correlation between having previous repairs and failure of subsequent repairs. However, Bukowski et $\mathrm{a}^{23}$ have demonstrated that the first attempt of the repair is best, and subsequent repairs become increasingly difficult.
There are several limitations of this study that could be addressed. First of all, this is a retrospective study, and like all such studies there are inherent biases and the conclusions cannot be strong. Second, the number of patients is too small to adequately assess the statistical significance of the findings; however, this is still a large number when compared to previous studies considering the fact that RUF is not very common. Third, the study compares multiple procedures, thus making the number within each subset even smaller.

This is one of the largest series of RUF, and even though definite conclusions cannot be drawn, the study still gives us an idea of the effective management of RUF. A larger randomized controlled trial, or at least a prospective trial, would be a more effective way to address some of the biases and lingering questions.

\section{Conclusion}

The overall success rate of the surgical treatment of RUF is high, regardless of the procedure type or of a patient's history of radiation. Routine fecal and urinary diversion seems to be unnecessary and should be used judiciously. Patients with previous repair attempts tend to have less favorable outcomes. 
We suggest less invasive and less morbid procedures should be attempted first due to the high success rates of repairs. In our current practice, the transanal repair is typically the initial approach.

\section{Acknowledgment}

The authors would like to thank Michael M Haniff for his help in the statistical analysis and editorial revisions of this paper.

\section{Disclosure}

The authors report no conflicts of interest in this work.

\section{References}

1. Chrouser KL, Leibovich BC, Sweat SD, et al. Urinary fistulas following external radiation or permanent brachytherapy for the treatment of prostate cancer. J Urol. 2005;173(6):1953-1957.

2. Vidal Sans J, Palou Redorta J, Pradell Teigell J, Banús Gassol JM. Management and treatment of eighteen rectourethral fistulas. Eur Urol. 1985;11(5):300-305.

3. Cools P, Vanderputte S, Van der Stighelen Y, Colemont L, Denis B. Rectourethral fistula due to Crohn's disease. Acta Urol Belg. 1996; 64(3):47-48.

4. Nyam DC, Pemberton JH. Management of iatrogenic rectourethral fistula. Dis Colon Rectum. 1999;42(8):994-997; discussion 997-999.

5. Hanus T. Rectourethral fistulas. Int Braz J Urol. 2002;28(4): 338-345.

6. Crippa A, Dall'oglio MF, Nesrallah LJ, Hasegawa E, Antunes AA, Srougi M. The York-Mason technique for recto-urethral fistulas. Clinics (Sao Paulo). 2007;62(6):699-704.

7. Wilbert DM, Buess G, Bichler KH. Combined endoscopic closure of rectourethral fistula. J Urol. 1996;155(1):256-258.

8. Hata F, Yasoshima T, Kitagawa S, et al. Transanal repair of rectourethral fistula after a radical retropubic prostatectomy: report of a case. Surg Today. 2002;32(2):170-173.
9. Razi A, Yahyazadeh SR, Gilani MA, Kazemeyni SM. Transanal repair of rectourethral and rectovaginal fistulas. Urol J. 2008;5(2):111-114.

10. Zmora O, Tulchinsky H, Gur E, Goldman G, Klausner JM, Rabau M. Gracilis muscle transposition for fistulas between the rectum and urethra or vagina. Dis Colon Rectum. 2006;49(9):1316-1321.

11. Zmora O, Potenti FM, Wexner SD, et al. Gracilis muscle transposition for iatrogenic rectourethral fistula. Ann Surg. 2003;237(4):483-487.

12. Wexner SD, Ruiz DE, Genua J, Nogueras JJ, Weiss EG, Zmora O. Gracilis muscle interposition for the treatment of rectourethral, rectovaginal, and pouch-vaginal fistulas: results in 53 patients. Ann Surg. 2008;248(1):39-43.

13. Renschler TD, Middleton RG. 30 years of experience with York-Mason repair of recto-urinary fistulas. J Urol. 2003;170(4 Pt 1):1222-1225; discussion 1225 .

14. Fengler SA, Abcarian H. The York Mason approach to repair of iatrogenic rectourinary fistulae. Am J Surg. 1997;173(3):213-217.

15. Mason AY. Trans-sphincteric surgery of the rectum. (with 2 colour plates). Prog Surg. 1974;13:66-97.

16. Yamazaki YR, Yago R, Toma H. Dartos flap interposition in the surgical repair of rectourethral fistulas. Int J Urol. 2001;8(10):564-567.

17. Etienney I, Rabahi N, Cuenod CA, Hoffmann P, Charachon A, Bauer P. Fibrin glue sealing in the treatment of a recto-urethral fistula in Crohn's disease: a case report. Gastroenterol Clin Biol. 2009;33(12): 1094-1097.

18. Lane BR, Stein DE, Remzi FH, Strong SA, Fazio VW, Angermeier KW. Management of radiotherapy induced rectourethral fistula. J Urol. 2006;175(4):1382-1387; discussion 1387-1388.

19. Santoro GA, Bucci L, Frizelle FA. Management of rectourethral fistulas in Crohn's disease. Int J Colorectal Dis. 1995;10(4):183-188.

20. Stephenson RA, Middleton RG. Repair of rectourinary fistulas using a posterior sagittal transanal transrectal (modified York-Mason) approach: an update. J Urol. 1996;155(6):1989-1991.

21. Sonoda T, Hull T, Piedmonte MR, Fazio VW. Outcomes of primary repair of anorectal and rectovaginal fistulas using the endorectal advancement flap. Dis Colon Rectum. 2002;45(12):1622-1628.

22. Joshi HM, Vimalachandran D, Heath RM, Rooney PS. Management of iatrogenic recto-urethral fistula by transanal rectal flap advancement. Colorectal Dis. 2011;13(8):918-920.

23. Bukowski TP, Chakrabarty A, Powell IJ, Frontera R, Perlmutter AD, Montie JE. Acquired rectourethral fistula: methods of repair. J Urol. 1995;153(3 Pt 1):730-733.
Research and Reports in Urology

\section{Publish your work in this journal}

Research and Reports in Urology is an international, peer-reviewed, open access journal publishing original research, reports, editorials, reviews and commentaries on all aspects of adult and pediatric urology in the clinic and laboratory including the following topics: Pathology, pathophysiology of urological disease; Investigation and treatment of

\section{Dovepress}

urological disease; Pharmacology of drugs used for the treatment of urological disease. The manuscript management system is completely online and includes a very quick and fair peer-review system, which is all easy to use. Visit http://www.dovepress.com/testimonials.php to read real quotes from published authors. 